\title{
Determination of Depth to Basement Using Spectral Analysis of Aeromagnetic Data over Azare Segment of Chad Basin
}

\author{
*Abdullahi Hussaini', Bello Yusuf Idi' ${ }^{2}$, Chifu E Ndikilar', Maharaz M Nasir'1, \\ Ahmad Alhassan ${ }^{183}$, Nasiru Bala ${ }^{185}$ Auwal Ibrahim ${ }^{1}$, Nasir Yakubu ${ }^{184}$, and Ibrahim Ayuba ${ }^{1}$ \\ ${ }^{1}$ Department of Physics, \\ Faculty of sciences, \\ Federal University Dutse \\ ${ }^{2}$ Department of Physics, \\ Faculty of sciences, \\ Modibbo Adama University, Yola \\ ${ }^{3}$ Department of physics, \\ Faculty of sciences, \\ Federal University of Kashere \\ ${ }^{4}$ Sule Maitama University \\ Kano \\ ${ }^{5}$ Physics Unit, \\ Science and Technology Department, \\ Umaru Ali Shinkafi Polytechnic \\ Sokoto.
}

Email: abdullahihussainimsa@gmail.com

\begin{abstract}
The high-resolution aeromagnetic data over part of the Bornu basin (sheet 84) north eastern (NE) Nigeria, was processed and interpreted using spectral analysis to determine the depth to the basement. The study area is bounded between longitude $10^{\circ} 00^{\prime} 00^{\prime \prime} \mathrm{E}$ to $10^{\circ} 30^{\prime} 00^{\prime \prime} \mathrm{E}$ and latitude $11^{\circ} 00^{\prime} 00^{\prime \prime} \mathrm{N}$ to $12^{\circ} 00^{\prime} 00^{\prime \prime}$. Regional residual separation of the total magnetic field intensity (TMI) was performed using polynomial fitting method. The residual map was divided into nine square spectral blocks using the filtering tool of Microsoft excel software. The Microsoft excel program employed Fast Fourier Transform (FFT) technique. It transforms the magnetic field data into the radial energy spectrum for each block. Then the average radial energy spectrum is computed in MATLAB. The result shows that depth to the deeper magnetic source ranges from $4503.9 \mathrm{~m}$ to $1948.3 \mathrm{~m}$. However, it can be observed that $N N, N E$, and NW are having less deep magnetic sources ranging from $1948 \mathrm{~m}$ to $2459.7 \mathrm{~m}$. The deepest sources happened at the major towns of interest which are Bidawa, Matsango, Yakiri and Fatara areas, Katagum Bauchi state ranging from $2632.8 \mathrm{~m}$ to $4503.9 \mathrm{~m}$ The maximum depth of the sedimentary unit was estimated as $4.5 \mathrm{~km}$ because the isolated value beyond this depth cannot be connected, and this depth occurs around Matsango and Bidawa. The shallow depth magnetic source map shows that SS, $S W, S E$ are having least shallow depth, central to northern part of the study area are having shallowest depth to the magnetic source.
\end{abstract}

Keywords: Depth to the basement, Spectral analysis, Aeromagnetic data, Azare, Chad basin.

*Author for Correspondence

Abdullahi Hussaini et al., DUJOPAS 7 (4b): 189-202, 2021 


\section{INTRODUCTION}

The Chad basin is among the Nigerian sedimentary basins with latitudes $11^{\circ} \mathrm{N}$ and $14^{\circ} \mathrm{N}$ and longitudes $9^{\circ} \mathrm{E}$ and $14^{\circ} \mathrm{E}$ in north eastern part of Nigeria with thickness $10 \mathrm{~km}$ (Avbovbo et al, 1986), $8 \mathrm{~km}$ (Nur, 2001)and 6.5km (Kwaya et al., 2013). It extends to five countries including Nigeria. There is little research especially on geophysical survey (Gravity and Magnetic) in the Chad basin. Amazingly none have been carried out in the Azare arm, which is also part of the Chad basin connecting Yobe and Jigawa State (Eletta and Udensi, 2012). The magnetic method offers innovative techniques for exploring the surface structure and mapping of lithology to infer the presence of detectable and significant contrast in physical properties of the sub-surface (Agunleti and Saua, 2015;Olashende, 2009; Obiora et al, 2015).

Magnetic data can be used to solve different exploration problems in many ways depending on the geologic setting and rock parameters (Okiwelku et al., 2013). Magnetic data can be analyzed to provide an insight to the element of petroleum exploration and production (Johnson, 1998). Magnetic data provides a low-cost way to screen or image a wide area as well as construct significant alternative models to delineate sub-surface structures and also reach a better understanding of the geophysics and the geology itself. Magnetic data also provide an insight into mapping basement surfaces and delineating shallower volcanic and shale or salt diapers in some cases. Aeromagnetic survey is applied for mapping the difference of the geomagnetic field, which takes place due to changes in the percentage of the rock's magnetite which reflects the variations in the distribution and type of magnetic minerals of the earth subsurface (Sunmonu and Alagbe, 2014).

This study is aimed at determining the depth to Basement of rocks using spectral analysis of aeromagnetic data over the Azare arm of the Chad Basin, Nigeria. This will improve the level of our understanding of the study area which has little or no research on this aspect and as well, the results could be used for future exploration campaigns in the Basin. Since there is a presence of petroleum in other sectors of the Chad basin, there is a probability of finding the same in the study area which is also part of the basin.

\section{MATERIALS AND METHOD}

\section{Study Area}

The study area (Azare Arm) is located at the North Eastern part of Nigeria. It is part of the Nigerian Chad Basin known locally as the Bornu Basin. The study area falls between longitude $10^{\circ} 00^{\prime} 00^{\prime \prime} \mathrm{E}$ to $10^{\circ} 30^{\prime} 00^{\prime \prime} \mathrm{E}$ and latitude $1100^{\prime} 00^{\prime \prime} \mathrm{N}$ to $12^{\circ} 00^{\prime} 00^{\prime \prime}$ enclosing Azare metropolis and surrounding villages such as Bidawa, Matsango, Udoji, Yakiri, Fatara and Kakudi village.

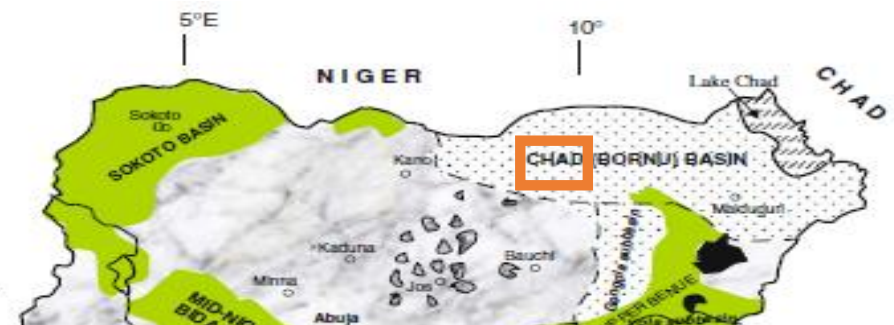


Figure 1: The Geologic map of Nigeria showing the location of the study area, red insert. (Modified after Obaje 2009).

\section{THE SOURCE OF DATA}

High-resolution aeromagnetic data used for this study were obtained from the Nigerian Geological Survey Agency (NGSA).

Since the release of aeromagnetic data in Nigeria by Nigeria Geological Survey Agency (NGSA), there has been an expansion of interest in the quantitative and qualitative interpretations of aeromagnetic data (Obiora et al., 2015). Interpretation of aeromagnetic survey data is aimed at mapping the surface and sub-surface regional structures (intrusive bodies, contacts, faults, basement rocks and mineralization). This could be performed both qualitatively and quantitatively.

The description of the survey results and the explanation of the major features exposed by a survey in terms of the types of likely geological formations and structures that brings about evident anomalies is what is refered to as qualitative Interpretation (Revees, 2005). This information is geared towards mapping surface and subsurface structures such as intrusive. The first step in qualitative interpretation is the preparation of the potential field maps or grids on which the anomalous values at different stations are plotted and on which contours are drawn at suitable intervals. The contour is done by interpolation using Oasis-Montaj Software and it was observed in the form of colored maps and grids.

Quantitative Interpretation involves making numerical estimates of the depth and dimensions of the sources of anomalies (Revees, 2005). The aeromagnetic quantitative interpretation technique adopted in this study is the Spectral analysis. In quantitative aeromagnetic data interpretation, we first need to apply mathematical filters. The filtering method employed is Reduction to pole (RTP).

Reduction-to-the-pole (RTP) is a filtering technique used to align the peaks and gradients of the magnetic anomalies directly over their sources. This provides a simple approach to improve realistic estimates of the source locations. This process locates the horizontal position of the source through the maximum amplitude of the reduced-to-the-pole anomaly; therefore, it assists in the geologic interpretation. The reduction to the pole (RTP) shifts the maximum of 
the magnetic anomaly to a position directly over its respective source modifying the shape of anomaly. This process simulates the field as if the anomaly was measured in the magnetic pole and the source had vertical magnetization, and therefore, the interpretative process is simplified. The RTP was introduced by Baranov(1957), formulated in the Fourier series by Bhattacharyya (1965) and improved to take advantage of the Fast Fourier transform algorithm by Kanasewich and Agarwal (1970). The operation can be viewed as a linear transformation and treated like a filtering operation (Gunn, 1975). In the wavenumber domain and in polar coordinates the RTP filter is defined as

$$
\mathrm{RTP}=\frac{1}{[j \cos ((I) \cos (D-\theta)(I)[j \cos (i) \cos (d-\theta)(i)]}
$$$$
\text { (4)(Silva, 1986) }
$$

where $j=\sqrt{-1}, \quad$ I and $\mathrm{D}$ are the inclination and declination of the geomagnetic field respectively, $\mathrm{i}$ and $\mathrm{d}$ are, respectively, the inclination and declination of the source magnetization vector, and $\Theta=\arctan \left(\mathrm{k}_{\mathrm{y}} / \mathrm{k}_{\mathrm{x}}\right)$ is the wave number direction, where $\mathrm{k}_{\mathrm{y}}$ and $\mathrm{k}_{\mathrm{x}}$ are the wave numbers in the $x$ and $y$ directions. On the denominator of the equation (4), the first and second terms inside the brackets depend on the magnetization directions of respectively the geomagnetic field (I and D) and the magnetized source (i and d).

\section{Spectral analysis}

The application of spectral analysis of potential field data to determine the depth and extent of the magnetic anomaly source is based on the radially averaged power spectra analysis of the data developed by Spector \& Grant (1970). Many authors including (Negi et al., 1983; Chiozzi, et al., 2005;Hsieh et al., 2014) used the method to determine the depth and extent of various magnetic sources of different shapes. The process involves 2-D Fourier Transform (FT) of magnetic data and computation of the radially averaged power spectra of transformed data. The power spectrum can be used to statistically estimate the depth to the top and bottom of the magnetic source.

The 2-D Fourier Transform FFT of a potential field data $f(x, y)$ is given by:

$\mathrm{F}\left(k_{x}, k_{y}\right)=\iint_{-\infty}^{\infty} f(x, y) e^{-i\left(k_{x} x+k_{y} y\right)} d x d y$

where $k_{x}$ and $k_{y}$ are wave numbers in $x$ and $y$ directions respectively measured in radian per unit of $x$ and $y$. The FT of a potential field due to a prismatic body has a broad spectrum with a peak at a location determined by the dimension and depth of the prism. The spectrum $F\left(k_{x^{\prime}} k_{y}\right)$ due to a prism is given by

$F\left(k_{x}, k_{y}\right)=e^{-h_{t} r}-e^{-} h_{b} r$

where $h_{t}$ and $h_{b}$ are respectively the depth to the top and bottom of the prism and $r=\sqrt{k_{x^{2}}+k_{y^{2}}}$

The peak wave number $\omega$ is given by

$\omega^{\prime}=\frac{\operatorname{In}\left(h_{b} / h_{t}\right)}{h_{b}-h_{t}}$

For a short wavelength (wavelength less than twice the thickness of the source, the radially averaged power density spectra $\Phi_{\Delta \mathrm{r}}(k)$ is defined as (Blakely, 1988)

$\Phi_{\Delta \mathrm{r}}(k)=\Phi_{M}\left(k_{x}, k_{y}\right) \times F\left(k_{x}, k_{y}\right)$

where $\Phi_{M}\left(k_{x}, k_{y}\right)$ is the power density spectra of the magnetization. $\Phi_{M}\left(k_{x}, k_{y}\right)$ is a constant and thus the radially averaged power spectra was expressed by Tanaka et al. (1999) for a randomly oriented magnetization as 
$\Phi_{\Delta \mathrm{r}}(k)=A e^{2 k z_{t}}\left[1-e^{-k\left(z_{b}-z_{t}\right)}\right]^{2}$

Where $A$ is a constant, and $Z_{b}$ and $Z_{t}$ are the depths to the bottom source respectively. The equation (10) can be written as

$\operatorname{In}\left[\Phi_{\Delta T}(k)\right]^{1 / 2} \operatorname{In} \mathrm{B}-K Z_{t}$

Thus the depth to the top of the source $Z_{t}$ can be approximated as the slope of the straight line fitting the low wave number (large wavelength) component of the spectrum. For magnetic data, the typical radially averaged spectrum is made up of three components: a deep sourced component which is related to low wave number, a shallow sourced component related to larger wave number and a noise component.

On the other hand, at the higher wave number, equation (11) is approximated as

$\operatorname{In}\left[\Phi_{\Delta T}(k)\right]^{1 / 2} / \mathrm{k}=\operatorname{In} \mathrm{D}-k Z_{O}$

(12) (Hsieh et al., 2014)

where $Z_{0}$ is the depth to the centroid of the source. Thus $Z_{0}$ can be obtained equally as the slope of a straight line fit to the spectra of low wave number component.

The method was applied on the aeromagnetic data of the study area using Oasis Montaj, Matlab and Grapher software.

\section{RESULTS AND DISCUSSION}

The total aeromagnetic field map of the study area Azare (Sheet 84), Nigeria after the removal of 33,000 nT by International Geomagnetic Reference Field (IGRF) is displayed in Fig. 2. The map is produced in colour aggregate, with pink to the red colour depicting high anomalies while green to blue depicts low anomalies.

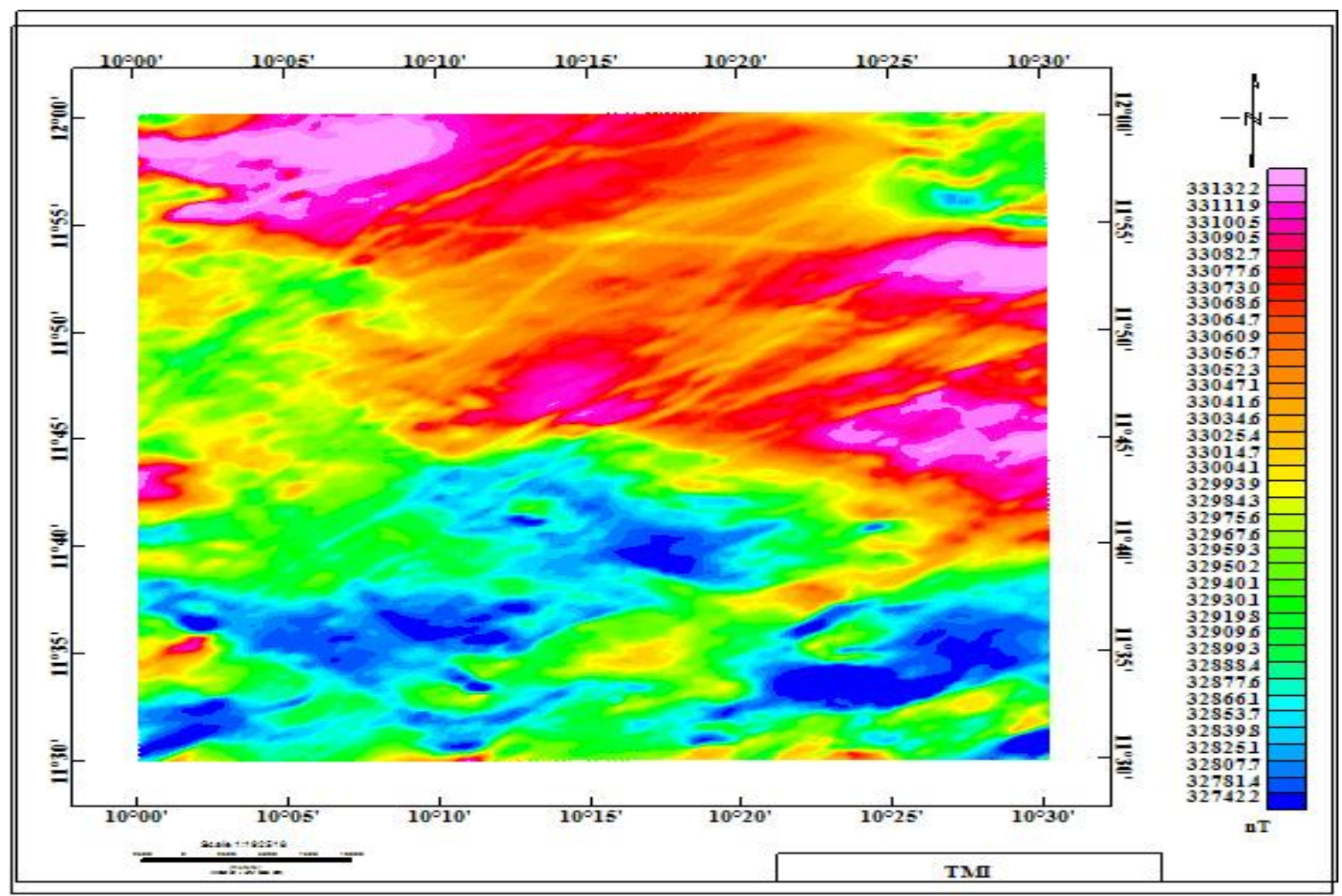

Figure 2: Total Magnetic Field Intensity of the Study Area

The Total Magnetic Intensity map of the study area in figure 2exhibits both considerable high and low anomalies ranging from $331322 \mathrm{nT}$ to $327422 \mathrm{nT}$. The North-eastern corner down to 
the eastern flank is dominated by very short wavelength closures which are high in the frequency of occurrence while south-western corner is dominated by a low short wavelength of low frequency of occurrence.

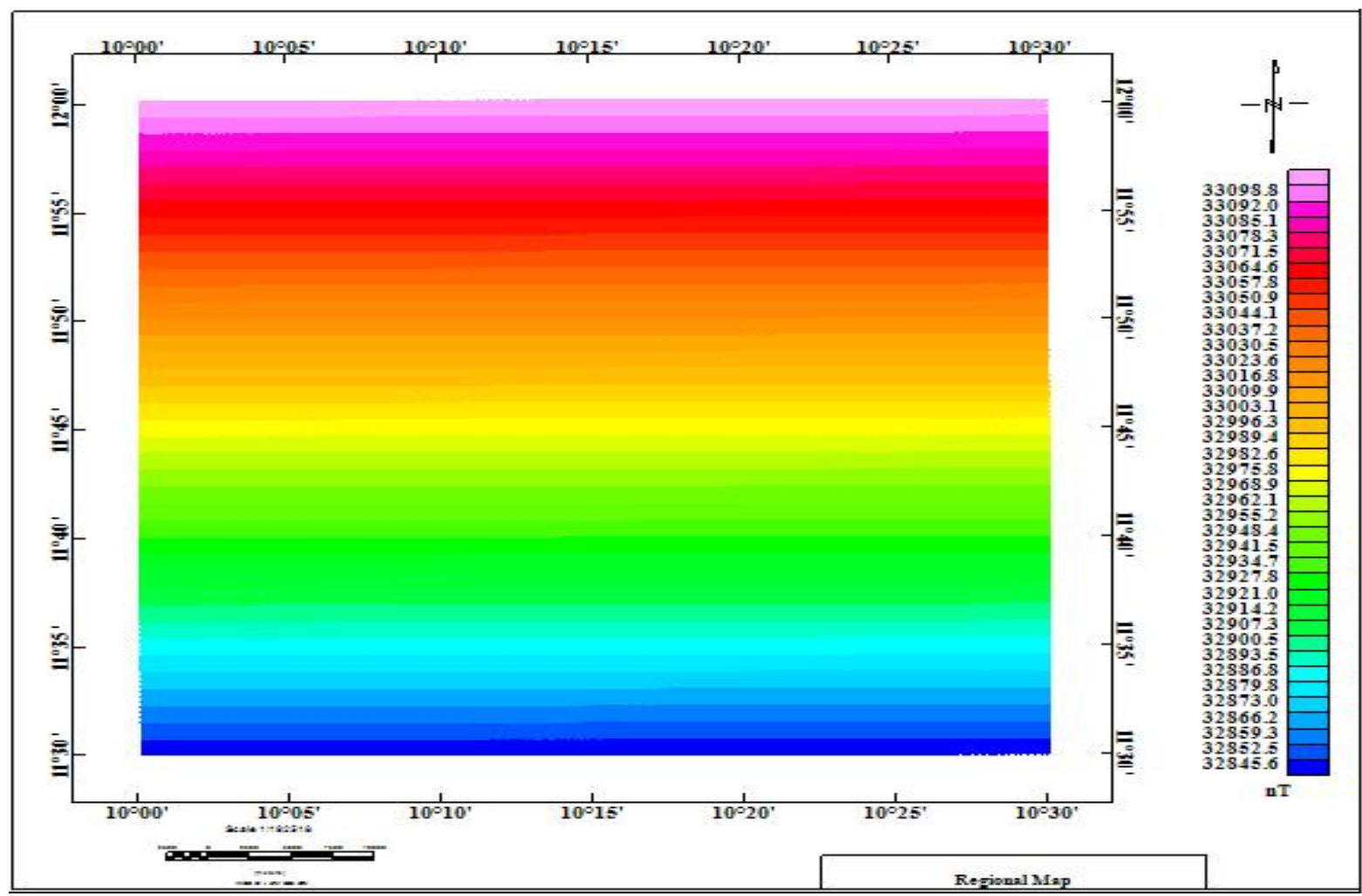

Figure 3: Regional Map of the Study Area

Regional maps of the study area was shown in figure 3. It was observed that the trend pattern of the regional field is S-N attributed to long period of marked thermo tectonic subsidence within the pan African rifts. 


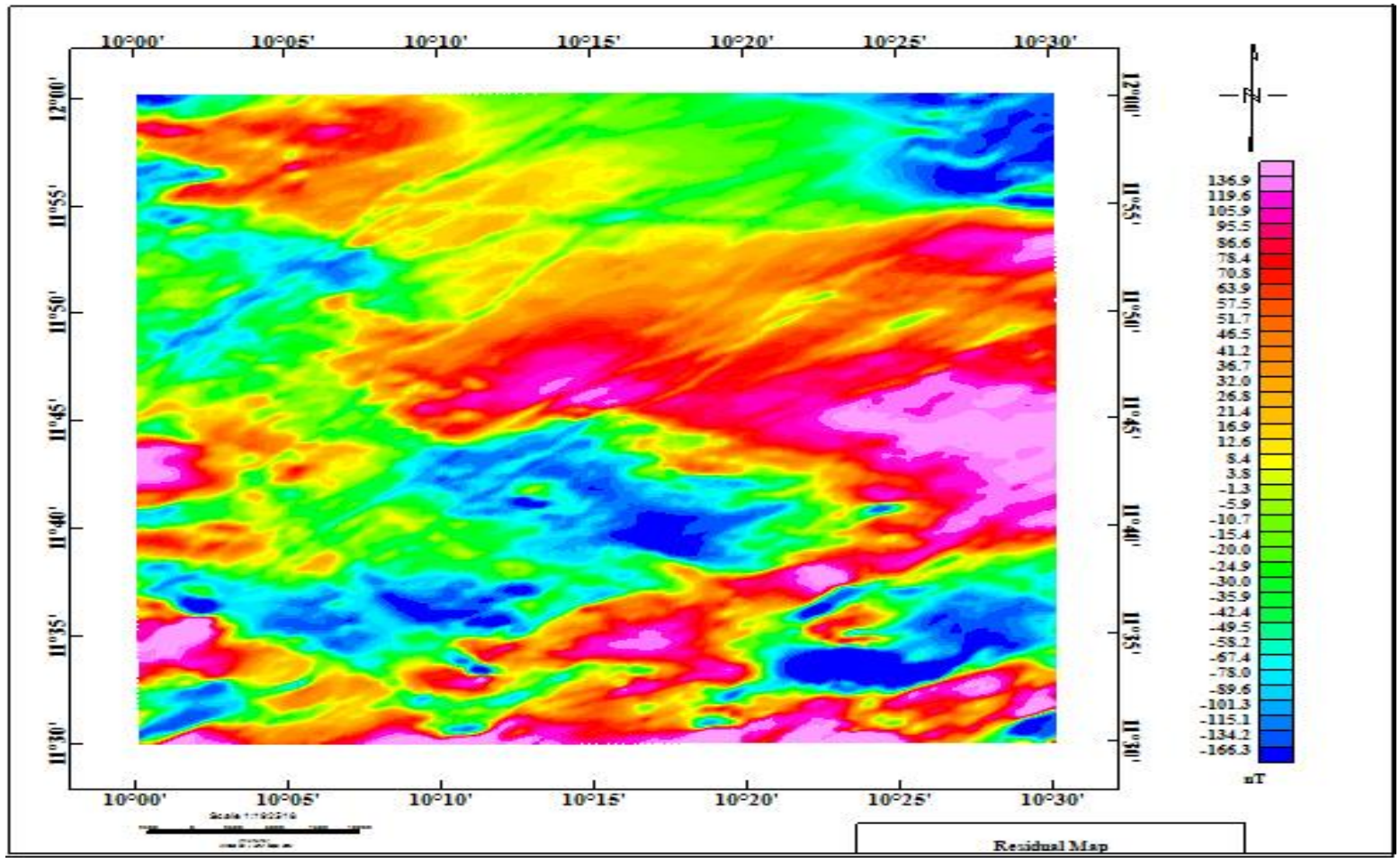

Figure 4: Residual Map of the Study Area

Residual map of the study area was produced in Figure 4 after the removal of regional data from the total magnetic field data. It shows distributed region of high, average and low magnetic intensity within the study area. The anomalous trend of the area trends NE-SW indicating the direction of subsurface lineaments controlling the geologic activities, this trend is obvious in the shaded relief map of residual (Figure 5). 


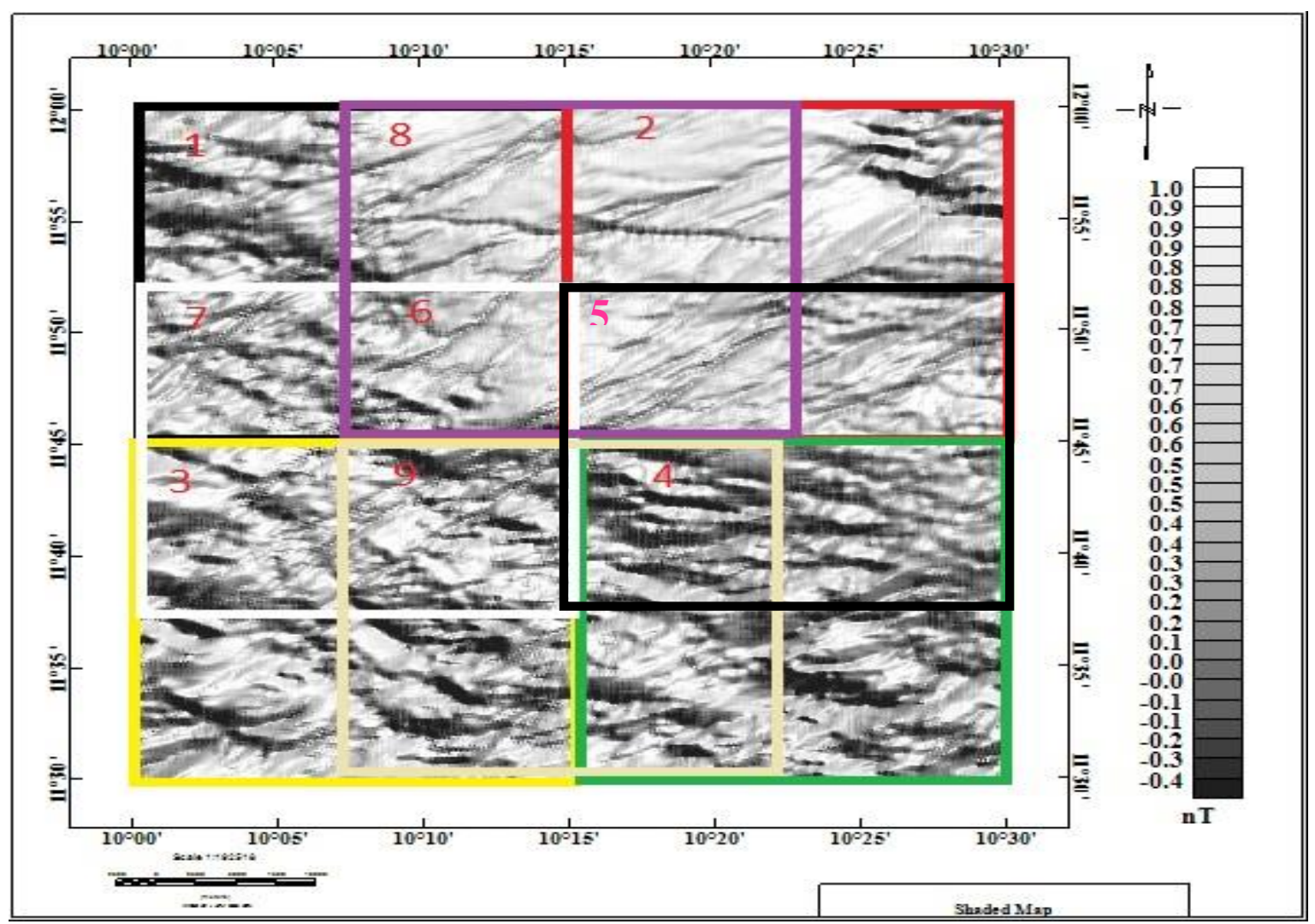

Figure 5: shaded relief map of residual data 

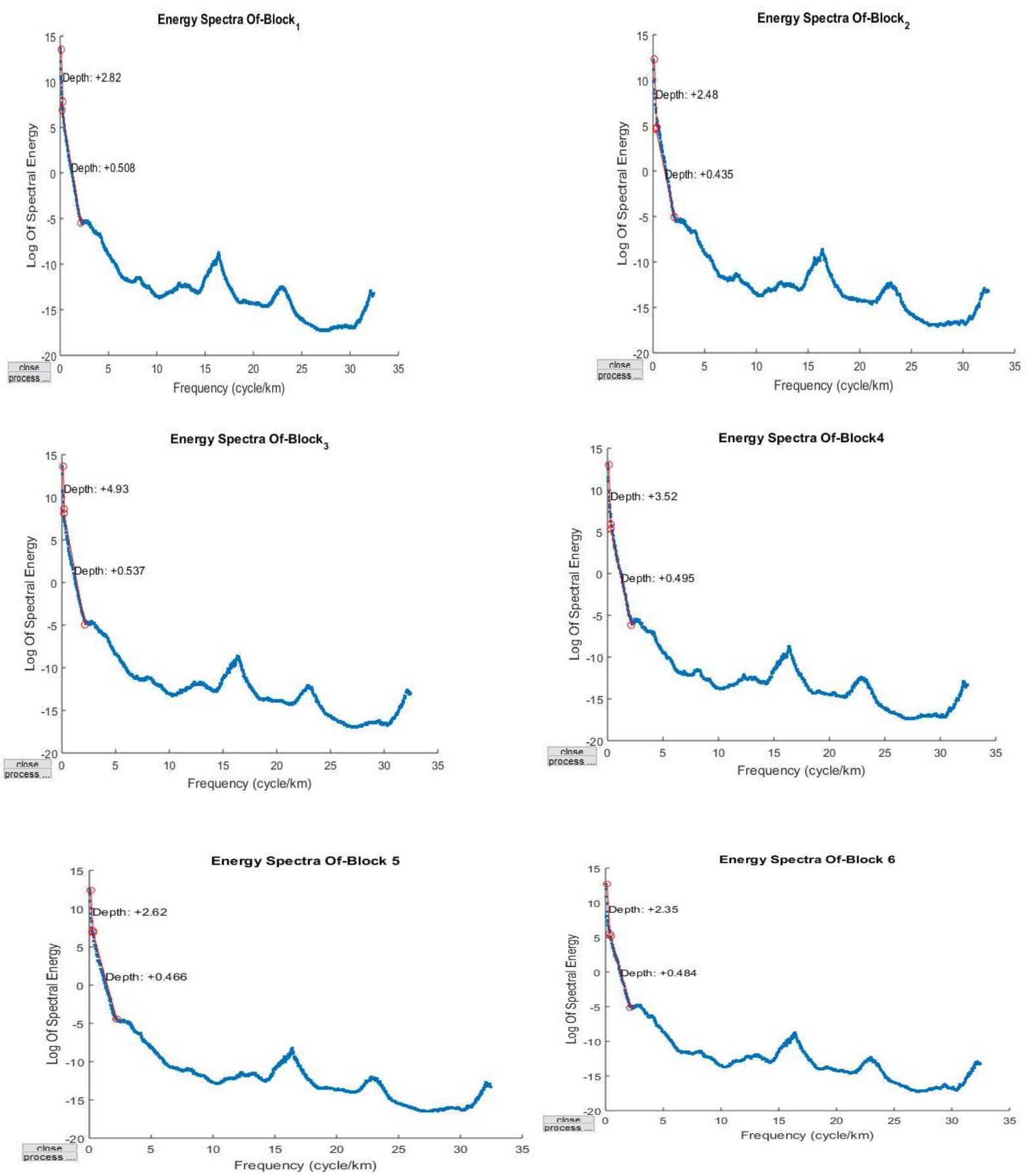

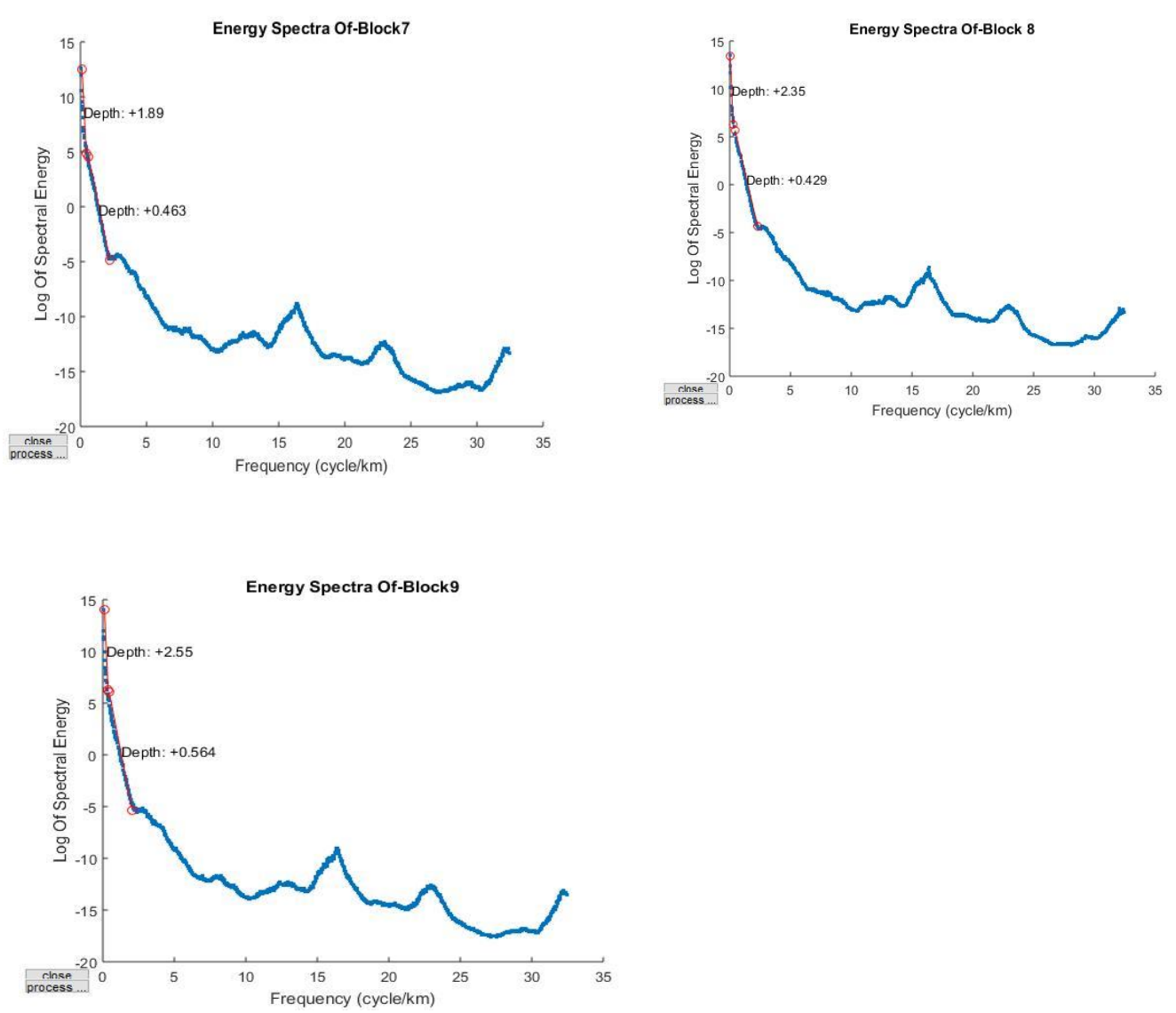

Figure 6 to 15: Results of the radially average power spectra used for the estimation of depths.

Deep and Shallow depth for blocks 1-9

Table 1: Values of the Shallow and Deep depths of the magnetic sources

\begin{tabular}{lllll}
\hline Block & $\begin{array}{l}\text { LONGITUDE } \\
\text { (Degrees) }\end{array}$ & $\begin{array}{l}\text { LATITUDE } \\
\text { (Degrees) }\end{array}$ & $\begin{array}{l}\text { Shallow Source } \\
(\mathbf{k m})\end{array}$ & $\begin{array}{l}\text { Deeper Sources } \\
(\mathbf{k m})\end{array}$ \\
\hline 1 & 10.24 & 11.75 & 0.508 & 2.82 \\
2 & 10.37 & 11.87 & 0.435 & 2.48 \\
3 & 10.12 & 11.63 & 0.537 & 4.93 \\
4 & 10.37 & 11.63 & 0.495 & 3.52 \\
5 & 10.11 & 11.87 & 0.466 & 2.62 \\
6 & 10.25 & 11.75 & 0.484 & 2.35 \\
7 & 10.13 & 11.75 & 0.463 & 1.89 \\
8 & 10.24 & 11.87 & 0.429 & 2.35 \\
9 & 10.24 & 11.62 & 0.564 & 2.55 \\
\hline
\end{tabular}

The depth to the top and depth to the bottom were estimated from the plots of Log of Spectral Energy against Frequency (Cycle/ km) as shown in Figures 6-15. The values of the deep and shallow depths to magnetic sources for each of the block were calculated and presented in Table 1 and their respective basal depth maps are shown in Figure 16 and 17. 


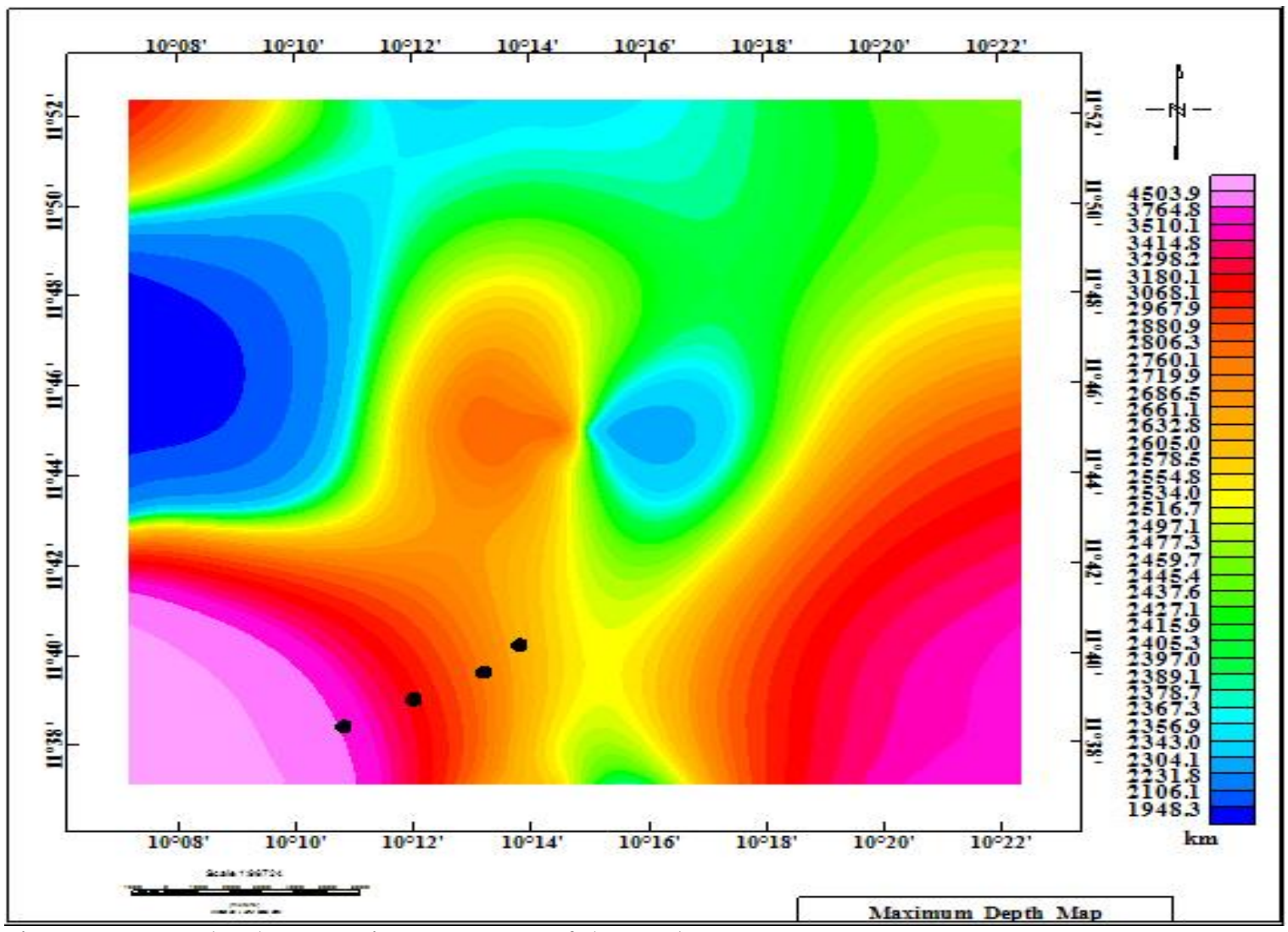

Figure 16: Deep depth Magnetic Source Map of the Study Area

It could be deduced that the deep depth to magnetic sources ranges from $4503.9 \mathrm{~m}$ to $1948.3 \mathrm{~m}$. However, it can be observed generally from Fig.18 that NN, NE and NW part are having less deep depth to the magnetic sources which ranges from $1948.3 \mathrm{~m}$ to $2459.7 \mathrm{~m}$ except for far NW. The central part have an intermediate deeper depth to the magnetic sources ranging from $2477.3 \mathrm{~m}$ to $2632.8 \mathrm{~m}$. SE, SS and SW having the deepest source to the magnetic anomalies which ranges from $2661.1 \mathrm{~m}$ to $4503.9 \mathrm{~m}$ having major towns of interest Bidawa, Matsango, Yakiri and Fatara within deeper to the deepest region of the study area. The Spectral Depth Analysis estimates the maximum depth of sedimentary units to be about $4.503 .9 \mathrm{~m}(4.5 \mathrm{~km})$ because the isolated values beyond this depth cannot be correlated and this depth occurs around Bidawa and Matsango areas. 


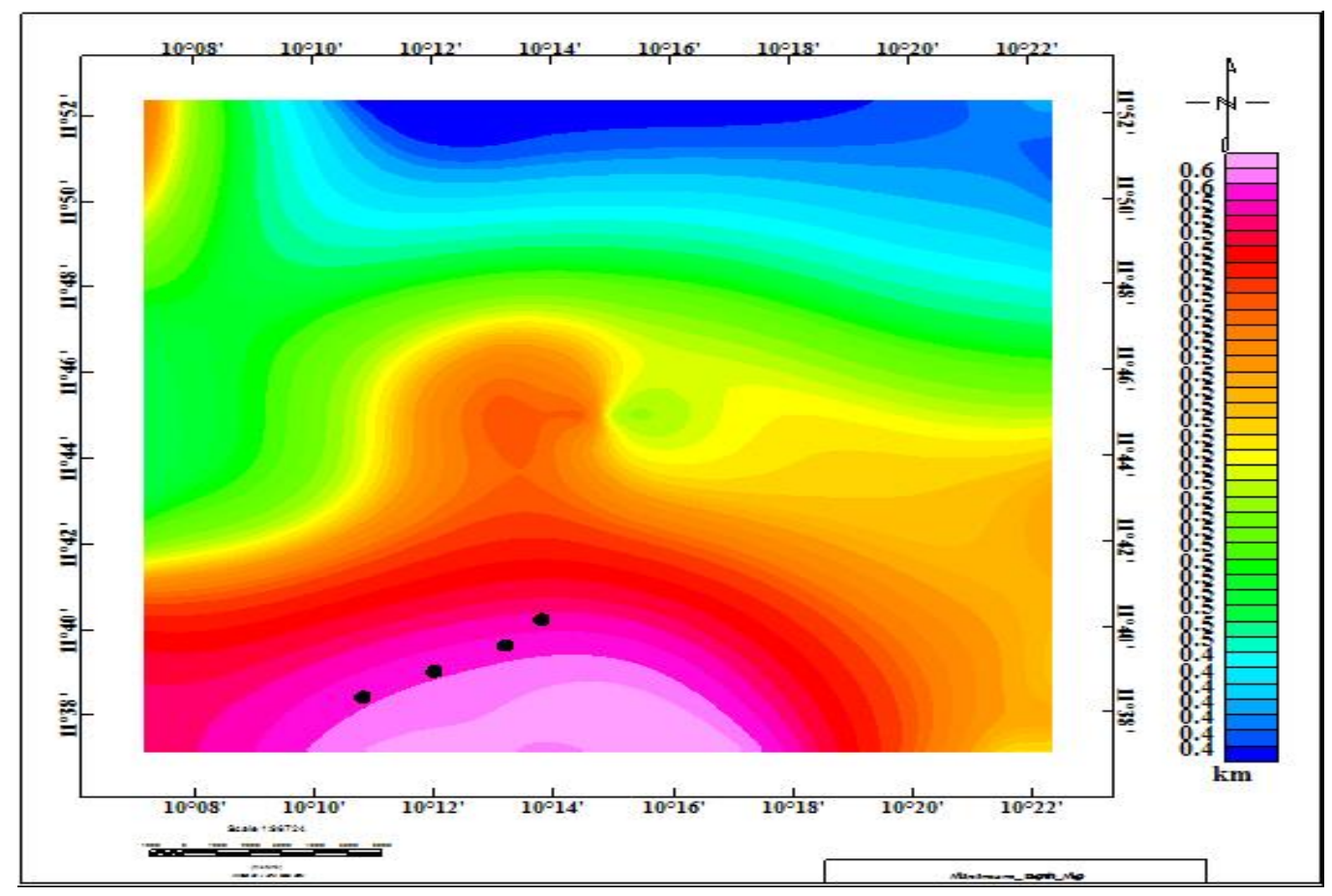

Figure 17: Shallow depth Magnetic Source Map of the Study Area

The shallow depth magnetic source map (Figure 17) shows the SS, SW and SE with least shallow depth, but Central to the Northern part of the study area having shallowest depth to the magnetic sources which is in line with fig 16.

This result is similar to the findings of Emmanuel et al (2011) that found their depth between 2.41 and 3.41 around Maiduguri arm of the Chad basin. Anakwuba and Chinwuko (2015) also found their depth within the eastern part of the Nigerian Chad Basin between $2.21 \mathrm{~km}$ and $14.07 \mathrm{~km}$. Babatunde et al.,(2019) in their research on part of the Chad basin found $5.7 \mathrm{~km}$ in depth from the result on Source Parameter Imaging (SPI) and from spectral analysis shows depth estimate of $1.2-4.8 \mathrm{~km}$. These values are not in conflict with the present finding because the depth range are very similar. The present study however shows areas that particularly have the tendency of accumulation of hydrocarbon. These areas did not receive special consideration by previous researchers.

\section{CONCLUSION}

A qualitative interpretation of the total magnetic intensity map over Azare (Sheet 84) reveals that NN, NE and NW region are predominantly of positive anomaly while the middle portion to the SS, SW and SE has less magnetic anomalies. The trend of regional field could be attributed to a long period of marked thermo-tectonic subsidence within the Pan African rifts. Spectral Depth Analysis reveals that the Bidawa, Matsango, Yakiri and Fatara areas have the deepest range of depths to the top of magnetic sources with an average depth ranging from $2661.1 \mathrm{~km}$ to $4503.9 \mathrm{~km}$, it also estimates the maximum depth of sedimentary units to be about $4503.9 \mathrm{~m}(4.5 \mathrm{~km})$ depth which occurs around Bidawa and Matsango areas inferring the regions of hydrocarbon deposit. Sedimentary thickness of $4.5 \mathrm{~km}$ is sufficient for hydrocarbon maturation. It is therefore recommended that; A detailed formation evaluation study using seismic reflection should be carried out in the study area to establish the liquid intrusion as well gas accumulation. 


\section{ACKNOWLEDGEMENT}

We acknowledge the effort of Nigerian Geological Survey Agency (NGSA) for providing the data used for this research.

\section{REFERENCES}

Abubakar Y. I, Umego M.N, and Ojo S.B. (2010). Asian Journal of earth Science, 62-72.

Agunleti, Y.S. and Saua, S.L. . (2015). Geochemical studies and exploration potential of the Oolitic-pisolitic Ironstone deposits of Agbaja Formation Southern Bida Basin, North Central Nigeria. International Journal of innovative science, Engineering and technology, $2(5), 527-528$

Arymanesh, M. (2009). Aeromagnetic data interpretation to locate buried faults in Yazd province- Iran. . World Applied Sciences Journal, 6(10) , 1429-1432.

Avbovbo AA, Ayoola EO, Osahon GA . (1986). Depositional and structural styles in the Chad Basin of northeastern Nigeria. AAPG Bull $70,1787-1798$.

Baranov, V. (1957). A new method for interpretation of aeromagnetic maps: Pseudogravimetric anomalies . Geophysics, 22,, 359-383.

Bhattacharyya, B. K. and Leu, L. K. . (1975). Analysis of magnetic anomalies over Yellowstone National Park: mapping and curie point isothermal surface for geothermal reconnaissance. . Geophys. Res., 80: , 4461-4465.

Blakely, R. (1988). Curie temperature analysis and tectonic implications of aeromagnetic data from Nevada. Journal of Geophysical Research, 93(B10) , 11817-11832.

Chiozzi P, Matsushima J, Y Okubo, V Pasquale . (2005). Curie Point Depth from Spectral Analysis of Magnetic Data in Central-Southern Europe. . Physics of the Earth and Planetary Interiors, 152(4), 267-276.

Eletta, B.E. and Odensi, E.E. . (2012). Investigation of the curie point Isotherm from the magnetic fields of Eastern Sector of Central Nigeria. . Geosciences, 2(4), 101-106.

Gunn, P. J. (1975). Linear transformations of gravity and magnetic fields. Geophysical Prospecting, 23, , 300-312. .

Hsien-Hsiang Hsieh, Chieh- Hung Chen, Pei Ying Lien, Horng- Yuan yen . (2014 ). Curie Point depth from Spectral Analysis of magnetic Data in Taiwan. . Journal of Asian Earth sciences, 90 , 26-33.

Johnson, E. A. (1998). Gravity and magnetic analyses can address various petroleum issues. Geologic applications of Gravity and Magnetic: case Histories. . In I. Gibson and P. S. Millegan. (Eds.). SEG Geophysical Reference (pp. 7-8). Tulsa, United States : No.8 and AAPG Studies in Geology (No. 43, .

Kanasewich, E. R., and R. G. Agarwal. (1970). Analysis of combined gravity and magnetic fields in wavenumber domain. Journal of Geophysical Research, 75, , 5702-5712. .

Kwaya, M.Y., Kurowska, E., Alagbe, S.A., Ikpokonte, A.E., Arabi A.S. . (2013). Evaluation of Depth to Basement Complex Cenozoic Unconformity from Seismic Profiles and Borehole in the Nigerian Sector of the Chad Basin. . Journal of Earth Sciences and Geotechnical Engineering Volume 3 (2), 43-49.

Lowrie, W. ,. (2007). Fundamentals of Geophysics. London: Cambridge University Press.

Murphy, B. (2007). Airbone Geophysics and the Indian scenario. . Journal of industrial Geophysics, 11(1), 1-28.

Negi J.G, Dimri V.P, P. K Agarawal, O.P Pandey . . (1986). A Spectral Analysis of the Aeromagnetic Profiles for Thickness Estimation of Flood Basalt of India. . Journal of the Australian Society of Exploration Geophysicist, 17(2), 105-111.

Nur, A. (2001). Spectral Analysis and Hilbert Transformation of Gravity Data over the Southwest of the Chad Basin, Nigeria. Journal of Mining Geology vol.37 (2) ,153-161. 
Obiora, D. N., Ossai, M. N. and Okwoli, E. . (2015). A case study of aeromagnetic data interpretation of Nsukka area, Enugu state, Nigeria, for hydrocarbon exploration. International Journal of Physical Sciences, 10(17) , 503-519.

Okiwelu, A. A. Ofrey-Kulo, O. and Ude, I. A. (2013). Interpretation of regional magnetic data offshore Niger Delta reveals relationship between deep basement architecture and hydrocarbon target. Earth Science Research, 2(1), 13-32.

Olasehinde, P. I. (2009). Investigation of the Geothermal Source Potential of part of the Niger-Delta Nigeria, using Aeromagnetic data. . 34-44: Unpublished M. Tech Thesis, Federal University of technology, Minna, Niger, State.

Onwuemesi, A. G. (1997). One-dimensional spectral analysis of aeromagnetic anomalies and Curie depth isotherm in the Anambra Basin of Nigeria. . Journal of Geodynamics,23(2), 95-107.

Rabeh, T. (2009). Prospecting for the ferromagnetic mineral accumulations using the magnetic method at the Eastern Desert, Egypt. . Journal of Geophysics and Engineering, 6(4), 401411.

Revees, C. (2005). Aeromagnetic Surveys; Principles, Practice and Interpretation. . GEOSOFT, 155.

Selly R.C. and Sonnenberg S.A. . (2014). Elements of Petroleum Geology:3rd edition,. San Diego: Academic Press. .

Spector, A. and Grant, F. ( 1970). Statistical models for interpreting aeromagnetic data. . Geophysics, 35(2), 293-302.

Sunmonu, L. A. and Alagbe, O. A. . (2014). Interpretation of Aeromagnetic Data of Kam, Using Semi-Automated Techniques. . International Research Journal of Earth Sciences, 2(2), 1-18.

Telford, W. M., Geldart, L. P. and Sheeriff, R. E. (1990). Applied geophysics (2 nd edition). Cambridge: Cambridge University press. . 